\title{
Cystathionine $\gamma$-Lyase-Hydrogen Sulfide Induces Runt-Related Transcription Factor 2 Sulfhydration, Thereby Increasing Osteoblast Activity to Promote Bone Fracture Healing
}

\author{
Yang Zheng, ${ }^{1,2, *}$ Feng Liao,,3,* Xianjuan Lin,, Fengjiao Zheng, Jinghui Fan, \\ Qinghua Cui, Jichun Yang, Bin Geng, ${ }^{1,2}$ and Jun Cai ${ }^{1}$
}

\begin{abstract}
Aims: Hydrogen sulfide (H2S) plays an essential role in bone formation, in part, by inhibiting osteoclast differentiation, maintaining mesenchymal stem cell osteogenesis ability, or reducing osteoblast injury. We aimed to investigate the role of $\mathrm{H} 2 \mathrm{~S}$ in osteoblast function and its possible molecular target.

Results: In this study, we found that cystathionine $\gamma$-lyase (CSE) majorly contributed to endogenous $\mathrm{H} 2 \mathrm{~S}$ production in the primary osteoblast. Overexpressed CSE increased osteoblast differentiation and maturation with higher bone morphogenetic protein 2 and osteopontin expression, alkaline phosphatase activity, and calcium nodule formation; in contrast, knockdown of CSE had opposite effects. Runt-related transcript factor 2 (RUNX2) is required for osteoblast biologic function. CSE-H2S increased nuclear RUNX2 accumulation, DNA binding activity, and target gene transcription. Protein sulfhydration is a common signal by H2S. We confirmed that RUNX2 was also sulfhydrated by H2S. This chemical modification enhanced RUNX2 transactivation, which was blocked by dithiothreitol (DTT, sulfhydration remover). Mutation of two cysteine sites in the runt domain of RUNX2 abolished H2S-induced RUNX2 sulfhydration and transactivation. In a bone -fracture rat model, overexpressed CSE promoted bone healing, which confirmed the effect of CSE-H2S on osteoblasts.

Innovation: CSE-H2S is a dominant $\mathrm{H} 2 \mathrm{~S}$ generation system in osteoblasts and promotes osteoblast activity by the RUNX2 pathway, with RUNX2 sulfhydration as a novel transactivation regulation.

Conclusion: CSE-H2S sulfhydrated RUNX2 enhanced its transactivation and increased osteoblast differentiation and maturation, thereby promoting bone healing. Antioxid. Redox Signal. 27, 742-753.
\end{abstract}

Keywords: osteoblast, differentiation, runt-related transcript factor 2, cystathionine $\gamma$-lyase, hydrogen sulfide, sulfhydration

\section{Introduction}

B ONE FORMATION OR BONE HEALING mainly depends on the action of two cell lineages: bone reabsorption cells (osteoclasts) and bone-forming cells (osteoblasts and their terminal differentiation cells, osteocytes, and bone-lining cells) (33). Osteoblasts play an essential role in bone syn- thesis, remodeling, and healing (29). Osteoblasts arise from mesenchymal stem cells (MSCs) dependent on bone morphogenetic protein (BMP) activation, runt-related transcription factor 2 (RUNX2) signaling, and other hormones $(33,36)$. Mature osteoblasts secrete collagens (type I collagen), osteocalcin $(\mathrm{OCN})$, bone sialoprotein (BSP), osteopontin (OPN), and proteoglycans such as decorin and

\footnotetext{
${ }^{1}$ Hypertension Center, Fuwai Hospital, Chinese Academy of Medical Sciences and Peking Union Medical College, State Key Laboratory of Cardiovascular Disease, National Center for Cardiovascular Diseases, Beijing, China.

${ }^{2}$ Department of Physiology and Pathophysiology, Department of Osteology-Peking University Third Hospital, Center for Noncoding RNA Medicine, Peking University Health Science Center, Beijing, China.

${ }^{3}$ Department of Orthopedics, Sichuan Provincial People's Hospital, Chengdu, China.

*These authors contributed equally to this work.
} 


\section{Innovation}

Sulfur-containing amino acids such as methionine or homocysteine have a role in bone diseases. Hydrogen sulfide $(\mathrm{H} 2 \mathrm{~S})$ is a metabolic production of homocysteine by a transsulfuration pathway dependent on cystathionine $\beta$ synthase and cystathionine $\gamma$-lyase (CSE). In this study, we identified CSE-H2S predominantly expressed in osteoblasts. CSE-H2S increased bone morphogenetic protein 2 secretion and enhanced runt-related transcription factor 2 (RUNX2) activity by sulfhydrating RUNX2 at the runt domain, thereby promoting osteoblast function in bone healing. A CSE agonist or H2S donor might be useful for treating osteoporosis or other bone diseases or treating hyperhomocysteinemia associated with bone injury.

biglycan into bone matrix (6). These components promote osteoid formation and osteocyte embedding. Therefore, osteoblast number and their maturation and differentiation ability are required for bone healing.

Hydrogen sulfide (H2S) is generated from L-cysteine catalyzed by cystathionine $\beta$-synthase (CBS), cystathionine $\gamma$-lyase (CSE), or a combined action of 3-mercaptopyruvate sulfurtransferase (MPST) and cysteine aminotransferase in mammals (16). Recent studies reported that H2S promotes bone fracture healing in rabbit (15) and attenuates bone loss induced by estrogen deficiency (12); however, the mechanism is unclear. H2S decreases osteoclast differentiation induced by nicotine or lipopolysaccharide (23) and osteoclast progenitor differentiation (11), which decreases necrotic bone absorption during bone healing, but benefits osteoporosis. As well, H2S decreases matrix metalloproteinase activity in bone matrix (34), thereby accelerating matrix mineralization. Finally, H2S promotes bone MSC mineralization by Wnt signals (12) and reduces MC3T3-E1 preosteoblast cell injury induced by H2O2 (39). CBS deficiency lowers MSC osteogenesis ability, which can be rescued by an $\mathrm{H} 2 \mathrm{~S}$ donor (26). However, the key enzyme generating $\mathrm{H} 2 \mathrm{~S}$ in osteoblasts and the role of the enzyme/H2S system in their maturation and differentiation activity and the molecular mechanism are unclear.

In this study, we aimed to investigate the role of $\mathrm{H} 2 \mathrm{~S}$ in osteoblast function and its possible molecular target. We found that CSE is the major expressed enzyme generating $\mathrm{H} 2 \mathrm{~S}$ in osteoblasts. Up- or downregulation of endogenous CSE mediates osteoblast differentiation, maturation, and mineralization. In conjunction with altered osteoblast differentiation and secretion function, RUNX2 nuclear accumulation and transcription activity were elevated by CSE-H2S. RUNX2 activity increased by $\mathrm{H} 2 \mathrm{~S}$ depends on sulfhydration modification at C123 and C132 cysteine residues. This chemical modification is a novel model of RUNX2 activation and essential for bone healing by $\mathrm{H} 2 \mathrm{~S}$.

\section{Results}

Osteoblasts predominantly express endogenous CSE-H2S system

We identified the endogenous $\mathrm{H} 2 \mathrm{~S}$ system in primary rat osteoblasts. CSE protein expression in isolated osteoblasts was similar to that in rat liver, with less CBS and no MPST expression in osteoblasts (Fig. 1A). Methylene blue assay was used to measure osteoblasts producing endogenous $\mathrm{H} 2 \mathrm{~S}(17.1 \mathrm{nmol} / \mathrm{mg} /$ mg protein); the CSE inhibitor DL-propargylglycine (PPG) or small interference RNA (siRNA) knockdown CSE inhibited about $69 \%$ or $56 \% \mathrm{H} 2 \mathrm{~S}$ production, respectively, whereas the CBS inhibitor aminooxyacetic acid (AOAA) or knockdown CBS inhibited only about $22 \%$ or $20 \%$, respectively (Fig. 1B). These findings suggest that CSE predominantly contributes to $\mathrm{H} 2 \mathrm{~S}$ generation in osteoblasts. Immunohistochemistry of femurs showed CSE strongly expressed in osteoblasts, osteoclasts, and bone marrow stromal cells and weakly in osteocytes (Fig. 1C).

\section{Endogenous CSE-H2S promotes osteoblast biologic activity}

To investigate the role of the endogenous CSE-H2S system in osteoblast activity, we overexpressed CSE by transfection of recombinant adenovirus (Supplementary Fig. S1A; Supplementary Data are available online at www.liebertpub .com/ars) or siRNA (Supplementary Fig. S1B) in isolated rat osteoblasts, then observed the markers of osteoblast differentiation and maturation during treatment with an osteogenic differentiation cocktail. Consistently, overexpressed CSE increased osteoblast H2S generation (Supplementary Fig. S1C), by contrast, knockdown CSE lowered it (Fig. 1B). We continuously observed osteoblast growth by MTT (3-(4, 5dimethylthiazol-2-yl)-2, 5-diphenyltetrazolium bromide) assay for 4 days. At the third and fourth day, osteoblasts, with CSE knockdown, exhibited higher cell growth than controls, whereas osteoblasts, with CSE overexpressed, showed reduced cell growth (Fig. 2A, $p<0.01$ ). On treatment with an osteogenic cocktail, BMP2 messenger RNA (mRNA) expression peaked on days 1 and 3 , then decreased on day 3 and returned to normal on day 7 (Supplementary Fig. S2). The mRNA expression for other markers, BSP, collagen $\alpha 1(\mathrm{I})$, collagenase- 3 , alkaline phosphatase (ALP), and osteoprotegerin (OPG), was similar (Supplementary Fig. S3). The expression of these genes was upregulated by CSE overexpression (Supplementary Fig. S2 and S3). In following experiments, mRNA detection was performed at 2 days after stimulation.

CSE overexpression increased ALP activity (Fig. 2B, $p<0.01$ ), ALP staining area (Fig. 2C, D, $p<0.01$ ), and Alizarin red-positive calcification nodules (Fig. 2E, F, $p<0.01)$; in contrast, CSE knockdown reduced these values (Fig. 2B-F). BMP2, OPG, and OPN as molecular markers of osteogenesis are secreted from osteoblasts and required for the development of bone and cartilage. CSE overexpression increased the expression of these markers (Fig. 3A, all $p<0.01$ ), whereas CSE knockdown decreased the values (Fig. 3B, all $p<0.01$ ). Thus, endogenous $\mathrm{H} 2 \mathrm{~S}$ as an autocrine molecule actively regulates osteoblast biologic activity, including differentiation, maturation, and mineralization.

\section{Endogenous CSE-H2S activates RUNX2 signals}

RUNX2 is a key transcription factor necessary for the osteoblast phenotype and an important downstream target of transforming growth factor $\beta$ (TGF- $\beta$ ) and BMP2 signaling (36). In this study, we assessed the role of RUNX2 in CSE$\mathrm{H} 2 \mathrm{~S}$-mediated osteoblast activity. CSE overexpression increased RUNX2 nuclear accumulation, and CSE knockdown 

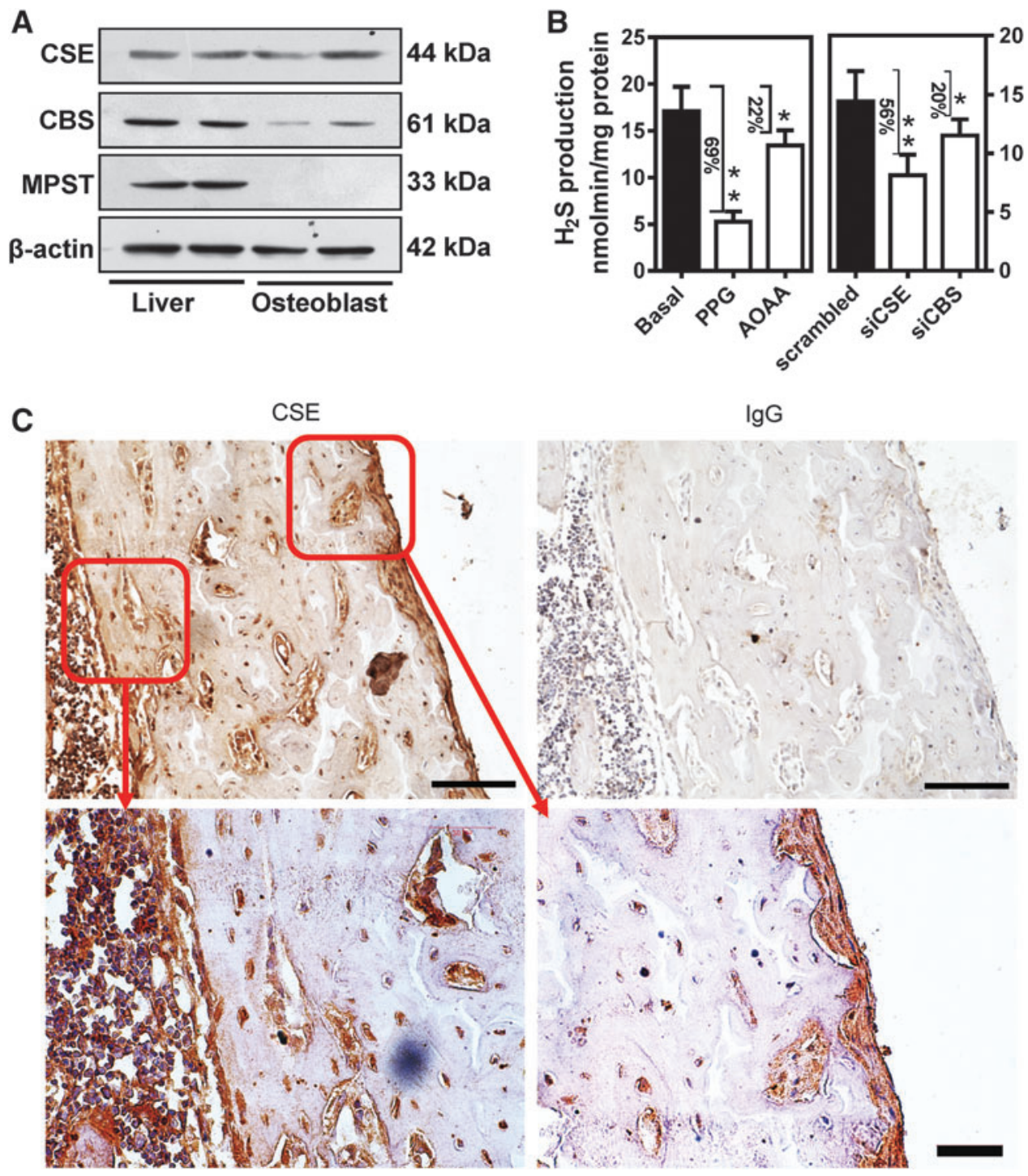

FIG. 1. CSE-H2S system mainly expressed in primary osteoblasts. (A) Western blot analysis of CSE, CBS, and MPST protein expression in osteoblasts and rat liver as a positive control. (B) Methylene blue assay of H2S product and PPG (CSE inhibitor, $3 \mathrm{mM}$ ) or AOAA (CBS inhibitor, $1 \mathrm{mM}$ ) was used to assess the $\mathrm{H} 2 \mathrm{~S}$ source. Data are mean \pm SD from 8 independent experiments. $* p<0.05, * * p<0.01$ versus basal group. (C) Immunohistochemical staining of CSE in rat left femur, mouse $\operatorname{IgG}$ as a negative control. Top panel: $\mathrm{bar}=100$ $\mu \mathrm{m}$; bottom panel: $\mathrm{bar}=20$ $\mu \mathrm{m}$. AOAA, aminooxyacetic acid; CBS, cystathionine $\beta$ synthase; CSE, cystathionine $\gamma$-lyase; H2S, hydrogen sulfide; MPST, 3-mercaptopyruvate sulfurtransferase; PPG, DLpropargylglycine; SD, standard deviation. decreased it (Fig. 4A, B, all $p<0.05$ ). Consistently, RUNX2 binding to osteoblast-specific element 2 (OSE2) of the OCN promoter increased while CSE overexpression (Fig. 4C). Accordingly, the mRNA levels of RUNX2 target genes ALP, collagen $\alpha 1(\mathrm{I})$, OCN, collagenase-3, and BSP were also increased (Fig. 4D, $p<0.01$ ). Conversely, CSE knockdown decreased RUNX2 activity (Fig. 4E, F). Therefore, CSE-H2S may activate RUNX2 signaling to upregulate osteogenic genes.

\section{H2S sulfhydrates RUNX2 at C123 and C132 sites and promotes its activity}

Post-translational modification such as phosphorylation of RUNX2 induces different activity regulation (36). Protein sulfhydration at cysteine sites is an important regulatory mode of H2S signaling (31). Using a modified biotin-switch assay, we first identified that NaHS induced endogenous RUNX2 sulfhydration in osteoblasts, which was removed by the desulfhydration reagent, dithiothreitol (DTT) (Fig. 5A). Accordingly, another H2S donor, GYY4137, increased (Fig. 5B) and the CSE inhibitor PPG decreased
RUNX2 sulfhydration (Fig. 5C). Chromatin immunoprecipitation (ChIP) assay revealed that NaHS increased RUNX2 binding to the OCN promoter, which was blocked by DTT (Fig. 5D).

RUNX2 has a conserved runt domain that is a DNA binding domain. This domain contains two closed cysteine sites (Supplementary Fig. S4). To determine whether sulfhydration occurred in two cysteine residues, we transfected wild-type human RUNX2 or C123 and C132 mutant RUNX2 gene into HEK-293 cells. In transfected wild-type human RUNX2 HEK-293 cells, NaHS increased RUNX2 sulfhydration and DTT decreased it (Supplementary Fig. S5). ChIP assay confirmed that sulfhydrated RUNX2 increased its binding ability to the OCN promoter, but DTT reduced it (Supplementary Fig. S6). Single C123S or C132S mutation partly abolished and double mutation fully abolished RUNX2 sulfhydration induced by $\mathrm{H} 2 \mathrm{~S}$ (Fig. 6A). As well, these mutations abrogated the effect of H2S on RUNX2 nuclear accumulation (Fig. 6B) and its DNA binding activity to the OCN promoter (Fig. 6C). Thus, C123 and C132 sites are major sulfhydration sites and new regulatory targets of RUNX2 activity. 
A
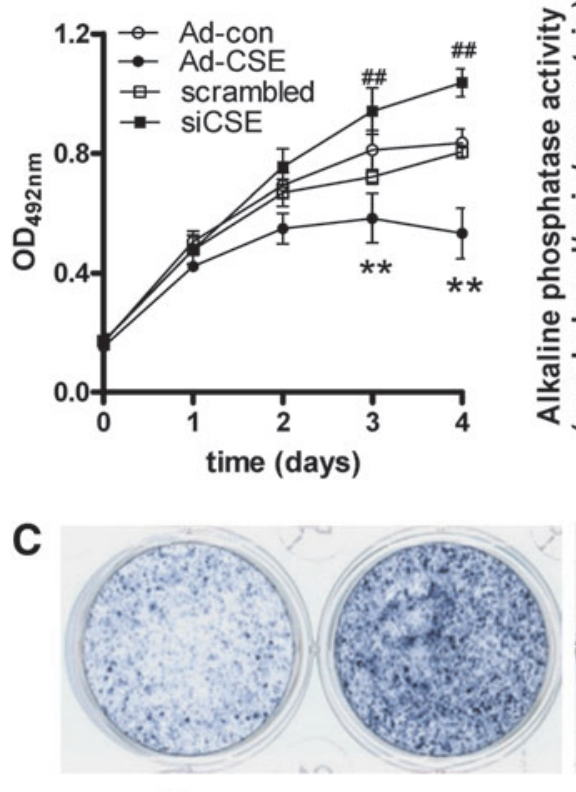

Ad-con

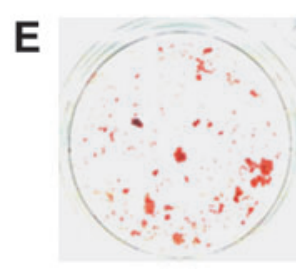

Ad-con

Ad-CSE

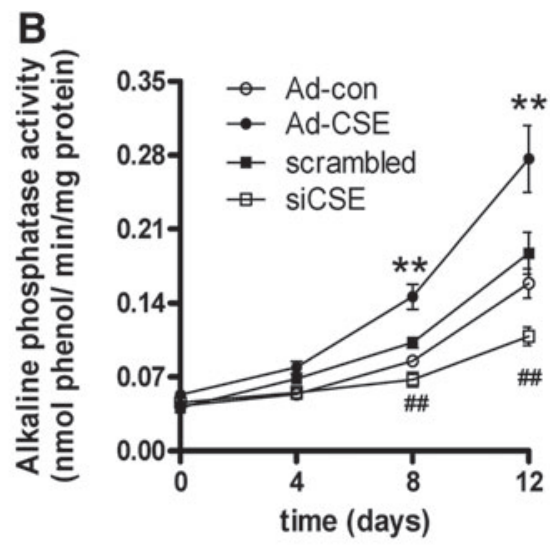

D
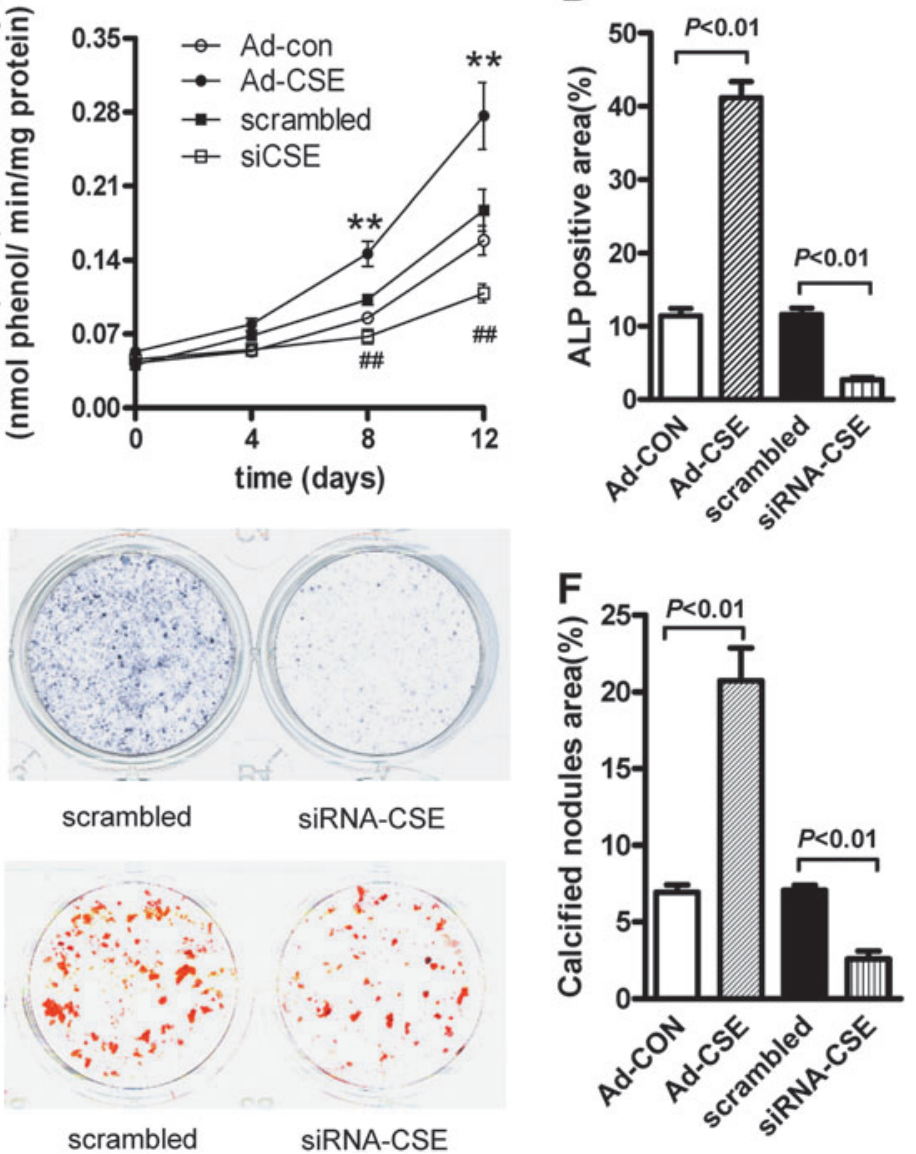

FIG. 2. Effect of CSE-H2S on ALP activity and calcium nodules in primary osteoblasts. CSE was overexpressed by adenovirus or knocked down by siRNA in primary osteoblasts, then cell growth was measured by MTT assay (A); ALP activity (B), ALP staining (C), and quantitative analysis (D). Calcium nodules were measured by Alizarin red staining (E) and quantified (F). Data are mean \pm SD from 12 independent experiments. ${ }^{* *} p<0.01$ versus control adenovirus, ${ }^{\# \#} p<0.01$ versus scramble RNA. ALP, alkaline phosphatase; MTT, 3-(4, 5-dimethylthiazol-2-yl)-2, 5-diphenyltetrazolium bromide; siRNA, small interference RNA.

A

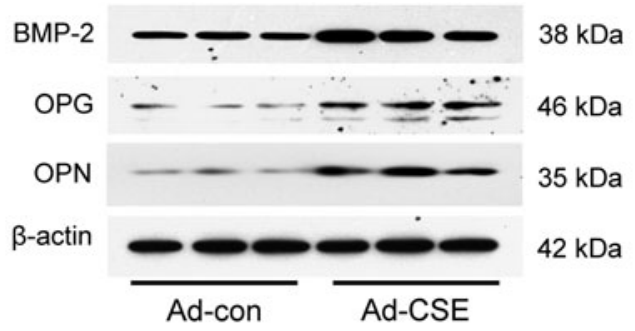

B
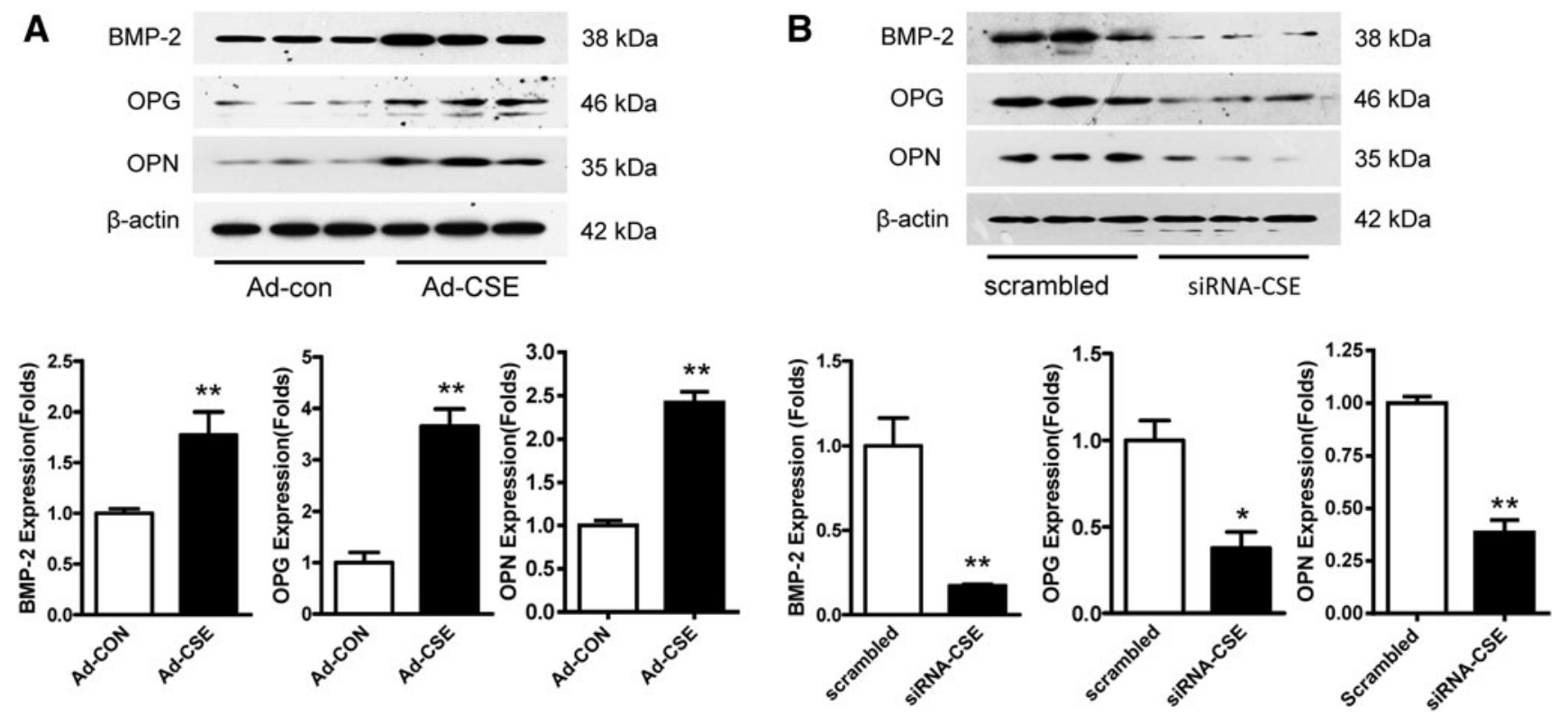

FIG. 3. CSE-H2S increased extracellular matrix protein expression. Western blot analysis of levels of extracellular matrix protein BMP2, OPG, and OPN with CSE overexpressed; $* * p<0.01 v s$ Ad-CON (A) or knocked down, ${ }^{*} p<0.05$, ${ }^{* *} p<0.01 v s$ scrambled (B). BMP2, bone morphogenetic protein 2; OPG, osteoprotegerin; OPN, osteopontin. 
A

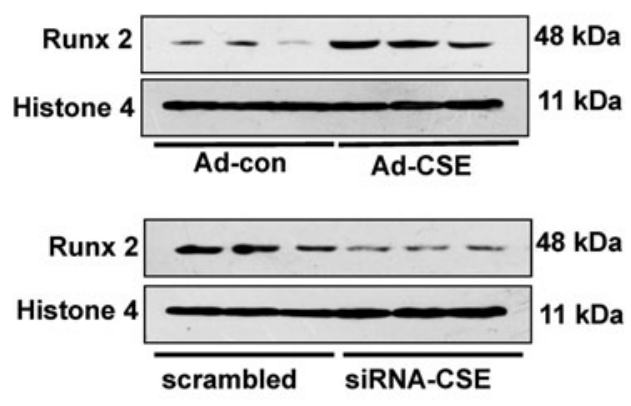

B

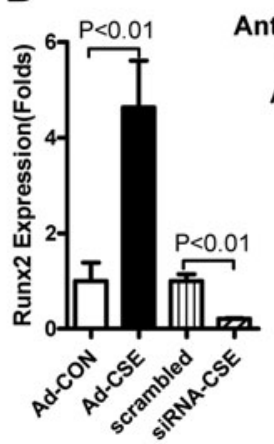

C

Anti-runx2 - - - + +

Ad-con - + - + -

Ad-CSE - - + ++

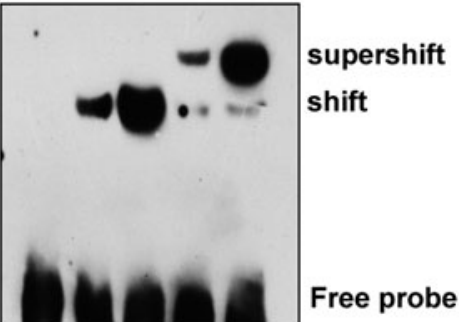

D

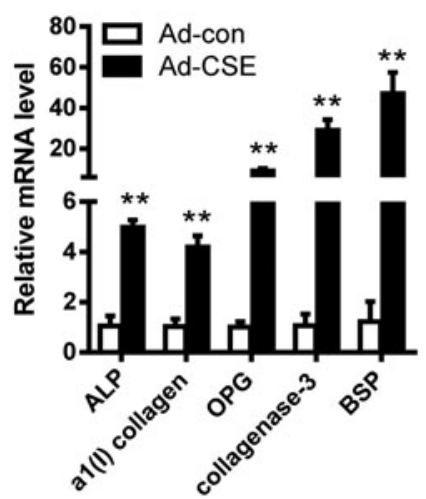

E

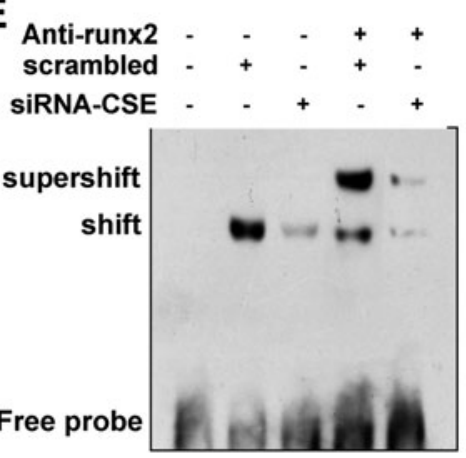

$\mathbf{F}$

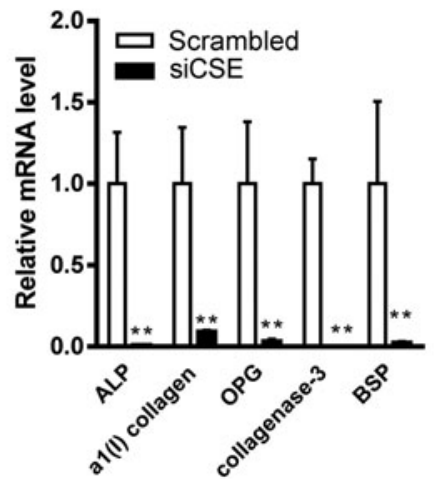

FIG. 4. CSE-H2S enhanced RUNX2 transactivation. (A) Nuclear RUNX2 expression was assayed with CSE overexpression or knockdown and changes were quantified (B). With CSE overexpression, RUNX2 binding to osteocalcin promoter (OSE2) was assessed by gel shift assay (C) as was its transactivation by target gene expression (D). With CSE knockdown, RUNX2 DNA binding activity was assessed (E) and also its target gene expression (F). Data are mean \pm SD from 6 independent experiments. ${ }^{* *} p<0.01$ versus control. mRNA, messenger RNA; OSE2, osteoblast-specific element 2; RUNX2, runt-related transcript factor 2.

\section{CSE-H2S promotes bone fracture healing in rat femur}

To investigate the effect of CSE-H2S in osteoblast activity in vivo, we implanted an absorbable gelatin sponge strip containing Ad-control or Ad-CSE $\left(10^{12} \mathrm{pfu}, 50 \mu \mathrm{L}\right)$ around the intramedullary fixed fractural bone in rat. The transfection effect was identified by green fluorescent protein control adenovirus (green fluorescence expressed in bone marrow, osteoblasts, and osteoclasts, Supplementary Fig. S7) and CSE immunohistochemical stain (Supplementary Fig. S8). Using microcomputed tomography scanning and $3 \mathrm{D}$ reconstruction, we observed that bone fracture lesion was well repaired by CSE adenovirus delivery for 2 weeks, with increasing trabecular number and reducing trabecular spacing (Fig. 7). By pathological stain analysis, CSE overexpression for 1 week, the local bone fracture showed less inflammatory cell infiltration (Fig. 8A), more collagen (Supplementary Fig. S9, red, yellow, and orange area), and fibrocartilage and osteocyte deposition (Fig. 8B). After 2 weeks, both edges of the defect were fused and the bone defect was closed (Fig. 8C) and almost filled with bone tissue (Fig. 8D).

\section{Discussion}

Sulfur-containing amino acids are closely associated with bone health. Methionine restriction or hyperhomocysteinemia is associated with low bone mineral density $(13,35)$ and increased bone fracture risk. $\mathrm{H} 2 \mathrm{~S}$ is a metabolic production of homocysteine by transsulfuration dependent on CBS, CSE, or MPST combined with cysteine aminotransferase (37). Recent studies highlight that $\mathrm{H} 2 \mathrm{~S}$ plays an essential role in osteoclast differentiation $(11,23)$ and bone marrow MSC osteogenesis (26). In this study, we identified that osteoblasts predominantly expressed the CSE-H2S system, which sulfhydrated RUNX2 at C122 and C132 sites to increase RUNX2 activity, thereby enhancing osteoblast biologic function to promote bone fracture healing.

Mature osteoblasts originate from bone marrow MSCs (33). Both CBS and CSE are expressed in MSCs, and CBS is necessary for MSC osteogenesis (26). However, the CSE role in MSCs is not fully investigated. The CBS-H2S function in MSCs depends on transient receptor potential cation channel subfamily V member 6 (TRPV6) channel sulfhydration to regulate intracellular $\mathrm{Ca} 2+$ concentration. The sulfhydration modification depends on $\mathrm{H} 2 \mathrm{~S}$ generation (27). CSE or CBS knockdown had similar effects on $\mathrm{H} 2 \mathrm{~S}$ generation and osteogenesis marker expression in MSCs (26). MSCs differentiated into osteoprogenitors and then preosteoblasts (6). Therefore, both CBS and CSE contribute to MSC differentiation. Primary osteoblast isolation and culture revealed that these cells express some osteoblast markers and are used for research in the stage of differentiation in early culture and mineralization in late culture (28). In MSCs, the expression 
A

FIG. 5. CSE-H2S sulfhydrated RUNX2 to increase its transactivation. Immunoprecipitation with RUNX2 antibody-linked biotinswitch assay to assess the RUNX2 sulfhydration with NaHS (A). Primary osteoblasts were treated with GYY4137-the H2S donor (B)-or PPG (C) for $12 \mathrm{~h}$, then RUNX2 sulfhydration was assessed with NaHS treatment. ChIP assay of RUNX2 transactivation and sulfhydration or desulfhydration by DTT treatment (D). Data are mean \pm SD from 5 independent experiments. ChIP, Chromatin immunoprecipitation; DTT, dithiothreitol.
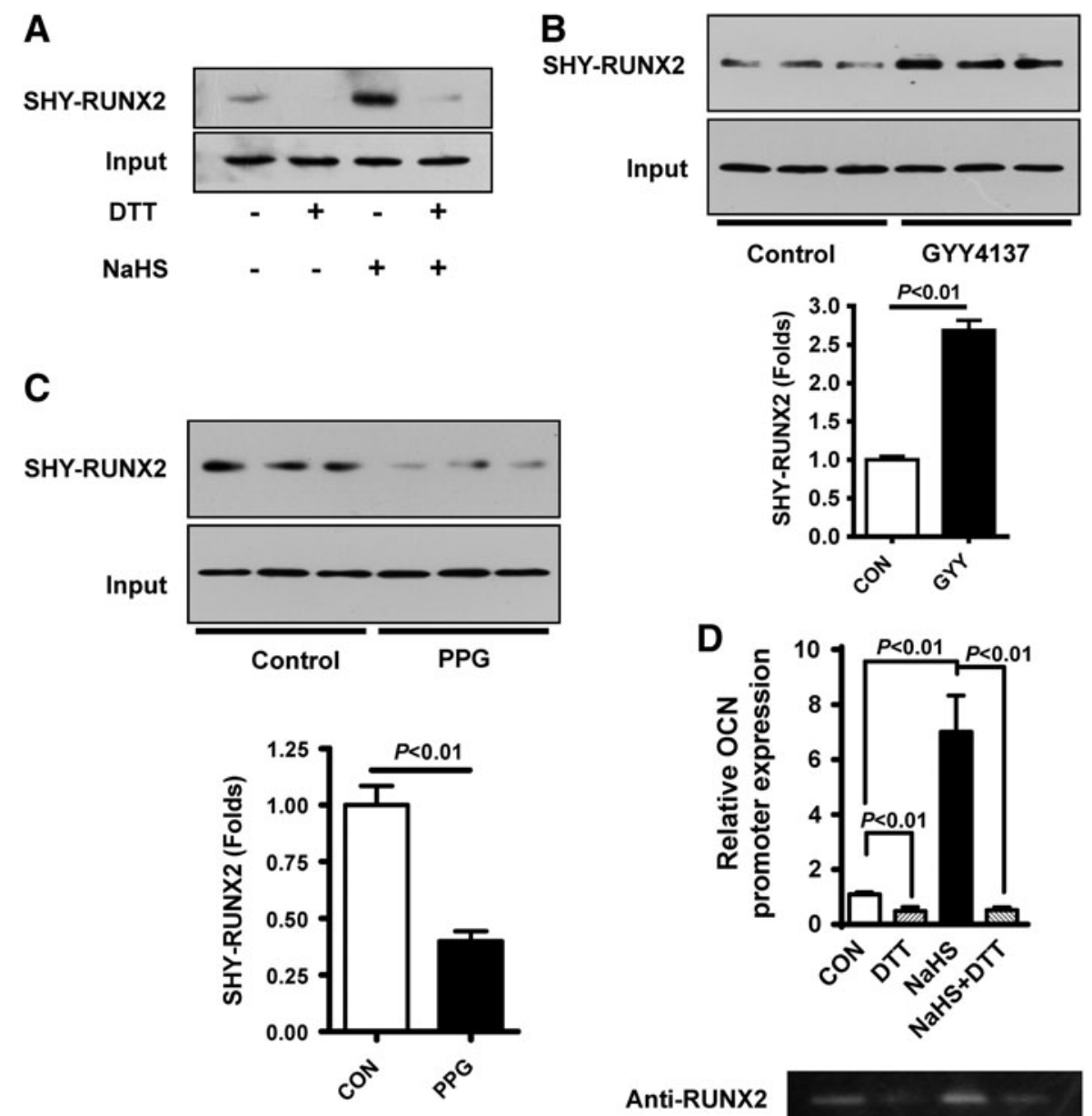
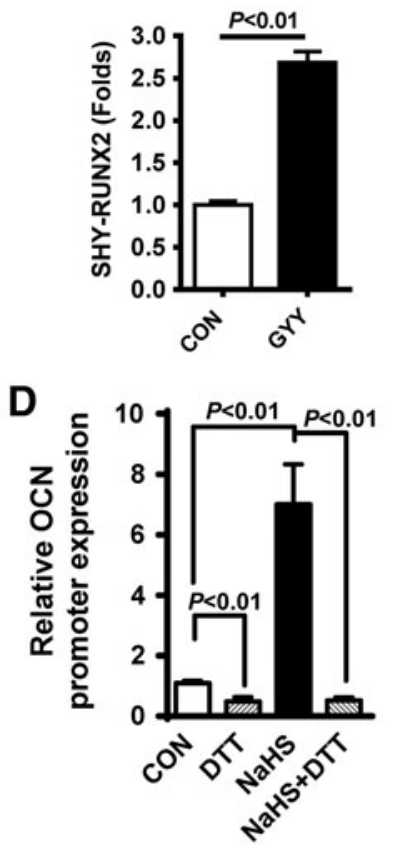

Anti-RUNX2

Input of CBS is higher compared with CSE (26), whereas CBS expression is lower in primary osteoblasts (Fig. 1). By comparison, inhibition of $\mathrm{H} 2 \mathrm{~S}$ production by the $\mathrm{CBS}$ or CSE inhibitor revealed that about $70 \%$ of $\mathrm{H} 2 \mathrm{~S}$ production was derived from CSE and 22\% from CBS in cultured osteoblasts. Knockdown CSE or CBS also confirmed the CSE role in generation of $\mathrm{H} 2 \mathrm{~S}$. Immunochemical staining confirmed that CSE protein was strongly expressed in MSCs and osteoblasts, but weakly expressed in osteocytes. Of note, CSE is the dominant enzyme to generate $\mathrm{H} 2 \mathrm{~S}$ from MSC to osteoblasts.

In this study, we also found that endogenous CSE-H2S promoted osteoblast biologic function such as increasing ALP activity, calcium nodules, and matrix protein expression (OPN, OPG, and BMP). Wnt5a and Wnt10b are critical in osteoblast differentiation $(2,17)$. Treatment with the H2S donor GYY4137 increased the mRNA expression of bone marrow Wnt10b and other Wnt family genes (12), which explains, in part, the effect of endogenous CSE-H2S on osteoblast differentiation.

BMPs are a TGF superfamily and required while bone marrow MSCs commit to an osteoblast lineage. Lack of BMP2, 4, and 7 in osteoblasts led to serious impairment of osteogenesis (1). Overexpressed CSE increased BMP2 mRNA and protein expression, so CSE-H2S may be essential in MSCs committing to an osteoblast lineage. CSE-H2S upregulating OPG is consistent with its effects on human periodontal ligament cells (24). Upregulated OPG inhibits osteoclast differentiation by binding to receptor activator of nuclear kappa B ligand (RANKL) and avoiding its interaction with RANK (21). CSE-H2S-elevated OPG level in osteoblasts may inhibit osteoclast differentiation $(11,23)$, thus promoting bone repair.

RUNX2, known as osteoblast-specific factor (Osf-2) or core-binding factor $\alpha$ (Cbfa1), is a master transcript factor for osteogenesis (18). RUNX2 deficiency arrests osteoblast differentiation, thereby causing complete lack of bone formation $(20,30)$. RUNX2 is also an essential downstream signal molecule of TGF- $\beta$ and BMP2 (22), promoting osteoblast maturation (40). An upregulated CSE-H2S system increased RUNX2 nuclear accumulation, DNA binding activity, and its target gene transcription, and inhibited CSE-H2S decreased them. These findings suggest that RUNX2 is involved in the effect of CSE$\mathrm{H} 2 \mathrm{~S}$ on osteoblast differentiation and maturation.

RUNX2 activity depends on protein expression as well as protein modifications such as acetylation, phosphorylation, sumoylation, and ubiquitination (3). RUNX2 sumoylation, ubiquitination, and acetylation are tightly linked with protein stability $(3,14)$, and acetylated RUNX2 shows increased transactivation activity (14). Phosphorylation is a common protein modification. RUNX2 has multiple 
A

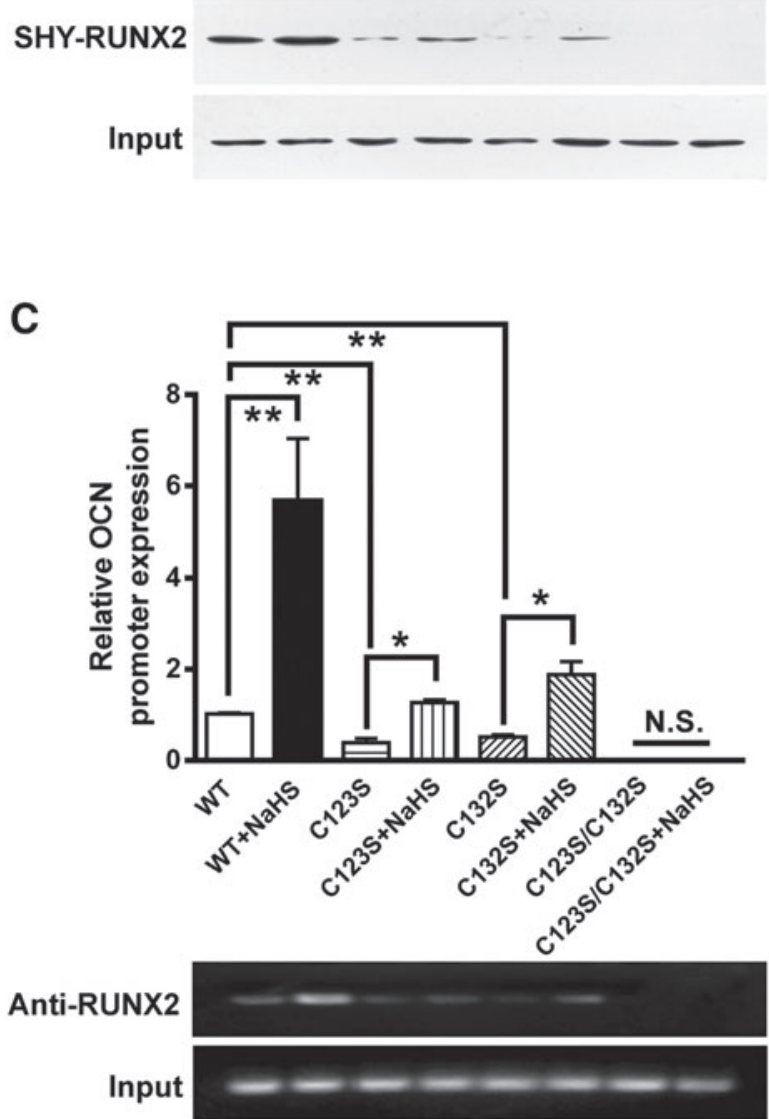

B
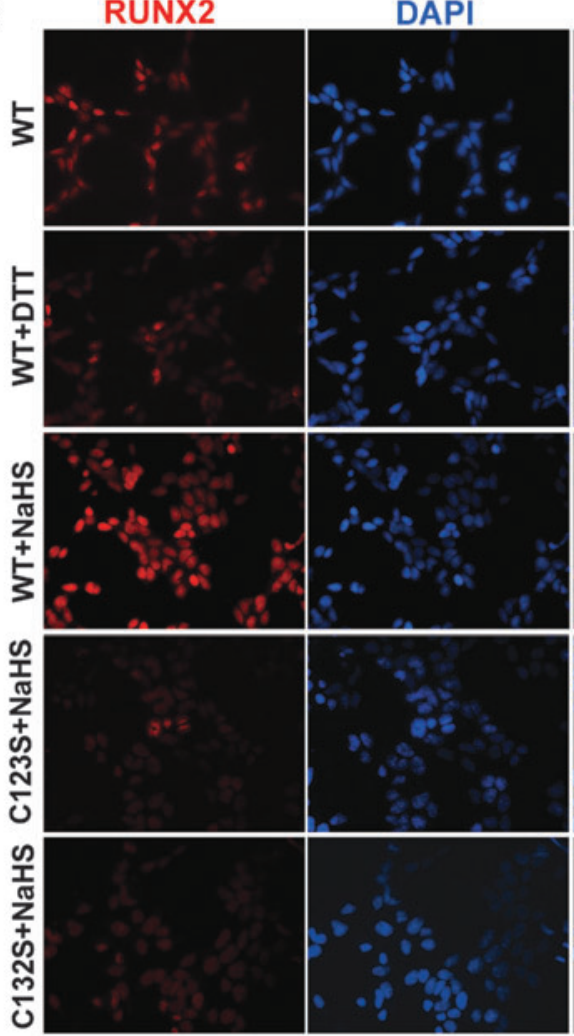

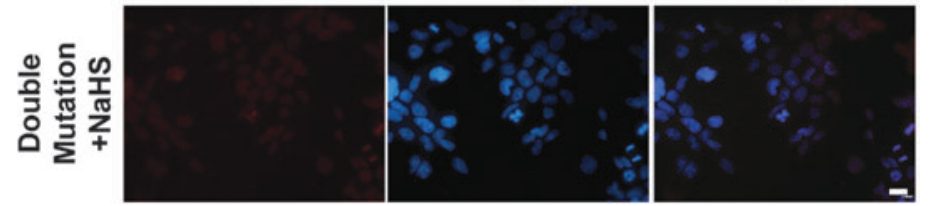

Merge
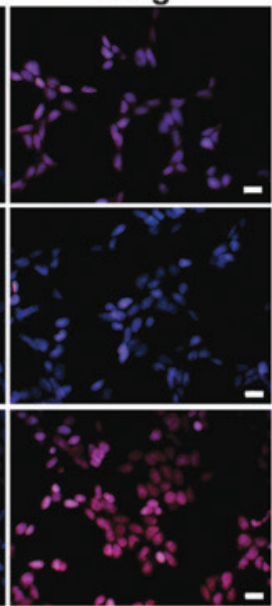

FIG. 6. C123 and $\mathrm{C} 132$ cysteine residues of human RUNX2 are major sulfhydration sites. Plasmids with C123 or C132 single or double mutation were transfected into HEK-293 cells, and RUNX2 sulfhydration was assayed by Western blot analysis (A). RUNX2 immunofluorescence staining with transfected plasmids (B), bar $=10 \mu \mathrm{m}$. ChIp assay of RUNX2 transactivation $(\mathbf{C})$. Data are mean \pm SD from 6 independent experiments. ${ }^{*} p<0.05$, $* * p<0.01$. N.S., normal saline; DAPI, 4',6-diamidino-2-phenylindole.

phosphorylation sites dependent on different kinases that enhance or inhibit its transactivation activity (36). H2S directly induces sulfhydration in the reactive cysteine residue of protein, a common signal of $\mathrm{H} 2 \mathrm{~S}$ (31). In this study, we demonstrated that RUNX2 was sulfhydrated by an H2S donor. Sulfhydrated RUNX2 increased its binding to the OCN promoter. The DNA binding domain of RUNX2 is a conservative region named runt, which has two cysteine residue sites, C123 and $\mathrm{C} 132$ (3). Mutation of the two sites abolished RUNX2 sulfhydration and its DNA binding activity. Thus, we identified a novel chemical modification (sulfhydration) of RUNX2 at C123 and C132 sites. Sulfhydated RUNX2 promotes its transactivation.

We also found that overexpressed CSE promoted bone fracture healing, with increasing collagen secretion, endochondral ossification, and a full bridge between fracture sites in rat femur. Overexpressed CSE increased endogenous $\mathrm{H} 2 \mathrm{~S}$ production, and then increased Wnt expression (12), sulfhydrated TRPV6, and promoted MSC differentiation into preosteoblasts (26); sulfhydrated RUNX2 at the runt domain thereby increased its transcription, consequently enhancing the expression of RUNX2 target genes OCN (8), collagen $\alpha$,
BSP, and OPN (9) to promote osteoblast extracellular matrix secretion and mineralization. H2S also increased BMP2 expression, an important molecule to induce osteoblast differentiation and biological function (1), but the molecular mechanism needs to be investigated.

Restricted feeding with the H2S precursor amino acid methionine caused bone mass loss (13) and reduced RUNX2 expression (32). In this study, we demonstrated that endogenous CSE-H2S has a role in osteoblast differentiation and maturation by inducing RUNX2 sulfhydration, thereby promoting bone healing (Supplementary Fig. S10), which may explain, in part, the changes in methionine deficiency and link sulfur-containing amino acid metabolism with bone diseases. RUNX2 is an important transcription factor and plays an essential role in osteogenesis (36), tumor progression and aggressiveness (7), chronic kidney diseases, and vascular calcification (4). Its transcript activity is mediated by chemical modification $(19,36)$. Our findings highlight a novel chemical modification of RUNX2 with H2S. This modification directly regulated DNA binding activity, which also illuminated that the $\mathrm{H} 2 \mathrm{~S}$ role in cancer and vascular calcification $(38,41)$ might partly involve RUNX2 sulfhydration. 


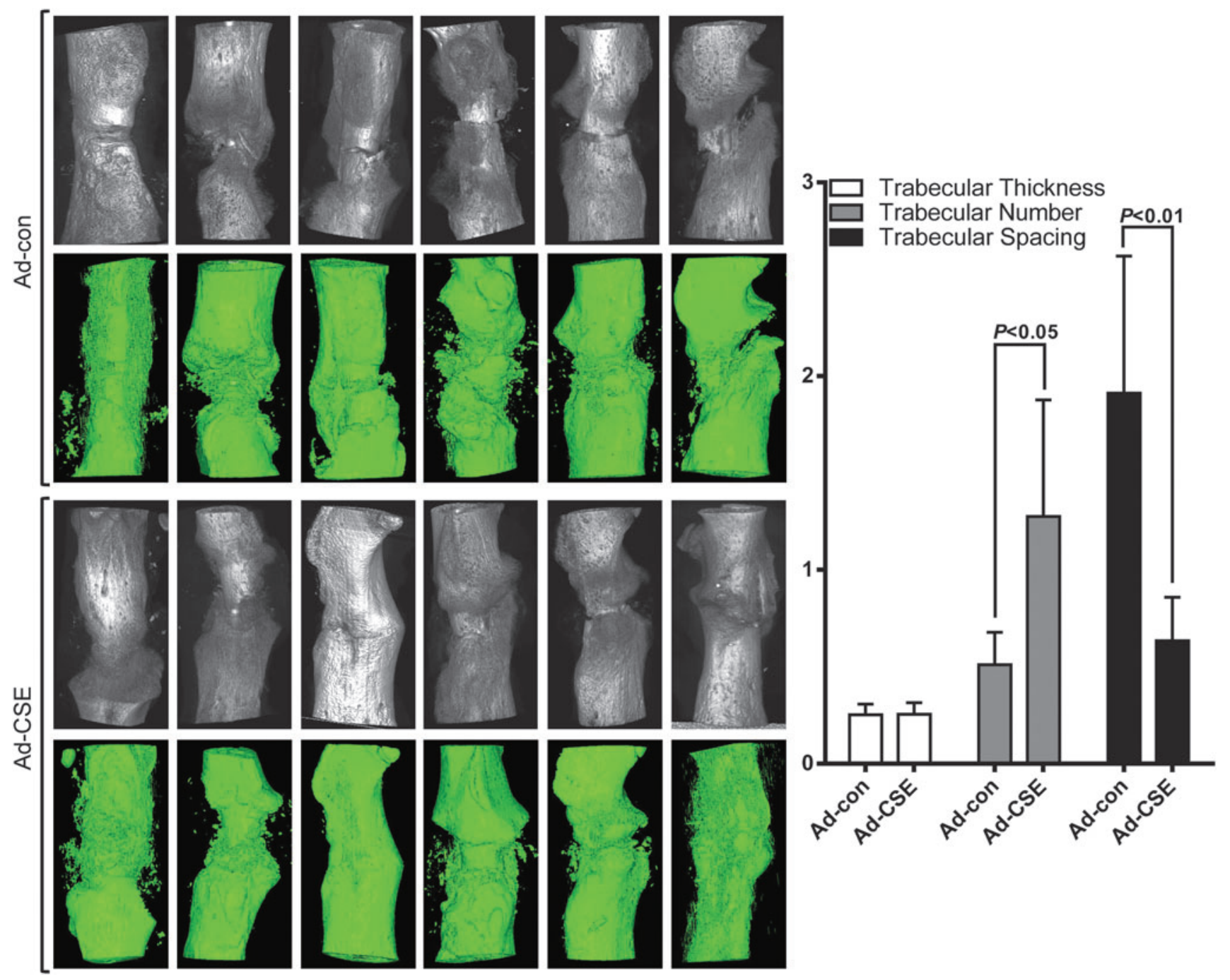

FIG. 7. micro-CT reconstruction image for femur fracture. CSE adenovirus delivery to local fracture for 2 weeks, and the femurs were scanned by a micro-CT and 3D reconstruction image is shown as gray image. The trabecular reconstruction images were placed under the bottom of gray image, and the trabecular thickness, number, and spacing were analyzed. CT, computed tomography.

\section{Materials and Methods}

\section{Animals}

All animal procedures complied with the Animal Management Rule of the Ministry of Health, People's Republic of China (Document No. 55, 2001), and the Care and Use of Laboratory Animals published by the U.S. National Institutes of Health (NIH Publication No. 85-23, updated 2011). The care and use of laboratory animals were approved by the Laboratory Animal Ethics Committee of Peking University. Neonatal or male Sprague-Dawley rats (8 weeks) were purchased from the Animal Center of Peking University Health Science Center.

With rats under general anesthesia, osteotomy was performed at the mid-shaft of the right femur by using a circular saw, $1.6 \mathrm{~cm}$ in diameter and $0.1 \mathrm{~mm}$ thick (Fine Science Tools, Foster City, CA), stabilized by intramedullary insertion of a sterilized 1.2-mm-diameter Kirschner wire (Stryker China, Hong Kong). An absorbable gelatin sponge strip $(1 \times 0.5 \times 0.2 \mathrm{~cm})$ containing an adenovirus control (Ad-con) or Ad-CSE (1012 plaque-forming units) was planted around the end of fracture. After surgery, penicillin $(10,000 \mathrm{U})$ was injected subcutaneously to prevent infection. At 1 or 2 weeks later, rats under anesthesia were killed by whole-blood bleeding and the femora were harvested. Four rats were sacrificed after a 2-week treatment with adenovirus, femurs were scanned by a microCT system (Scanco microCT40; SCANCO Medical, Swiss), and 3D image was reconstructed to assess the bone fracture repair.

\section{Primary osteoblast isolation}

Primary osteoblasts were isolated from skull bones of neonatal rats as described (28). Briefly, the skull bone was rinsed with sterile phosphate-buffered saline (PBS), minced to small pieces, digested with $0.25 \%$ trypsin $(10 \mathrm{~min})$, and then $0.2 \%$ collagenase II ( 3 times, first $30 \mathrm{~min}$, then other times $120 \mathrm{~min}$ ). The second and third collagenase digestions were filtered through a $200-\mu \mathrm{m}$ sieve and spun at $1500 \times g$ for $5 \mathrm{~min}$, then the cells were resuspended in Dulbecco's Modified Eagle 
A

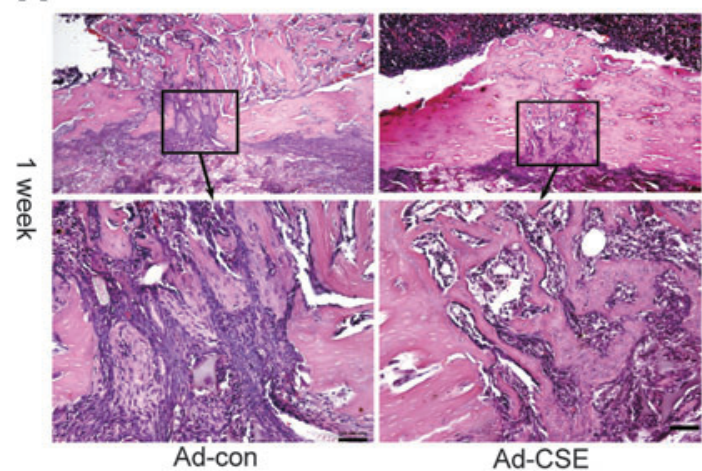

C

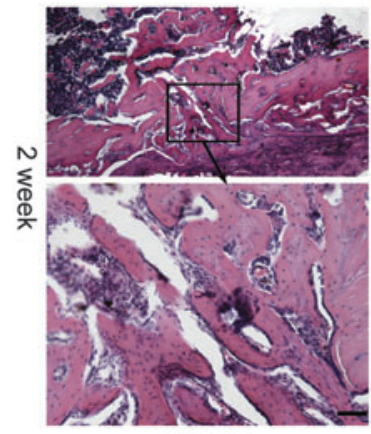

Ad-con

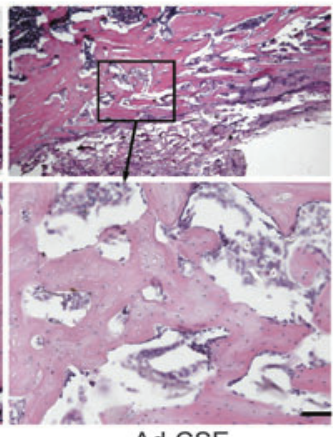

Ad-CSE
B

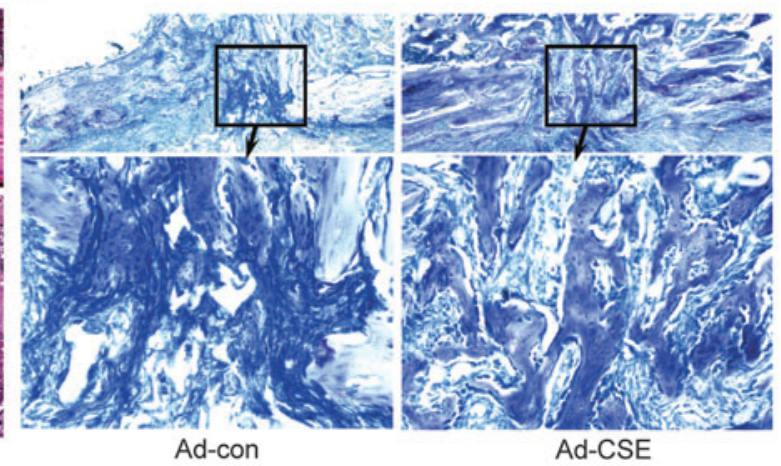

D

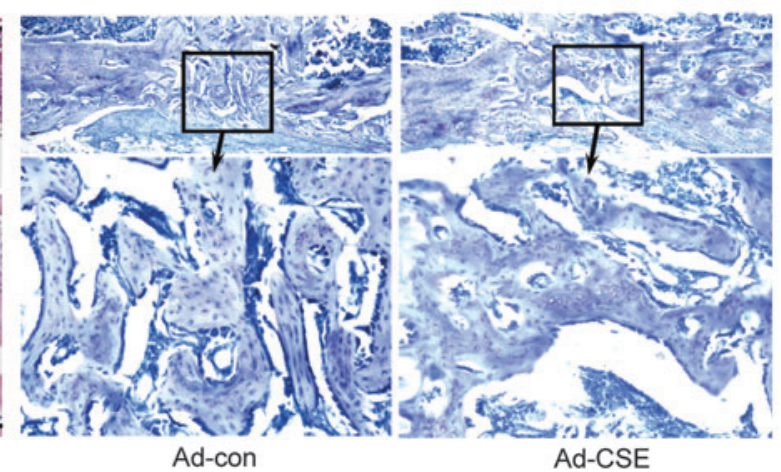

FIG. 8. Effect of CSE overexpression on bone healing. In the rat right femur fracture model, a gelatin sponge strip with CSE adenovirus was planted in the intramedullary fixed fractured bone for 1 week $(\mathbf{A}, \mathbf{B})$ or 2 weeks $(\mathbf{C}, \mathbf{D})$. Hematoxylin and eosin staining $(\mathbf{A}, \mathbf{C})$ and toluidine blue staining $(\mathbf{B}, \mathbf{D})$ used to assess bone healing. Bar $=100 \mu \mathrm{m}$.

Medium (DMEM) (with $10 \%$ fetal calf serum [FBS]), seeded in a plate, and incubated at $37^{\circ} \mathrm{C} / 5 \%$ carbon dioxide.

\section{Adenoviruses and siRNA transfection}

For adenoviral infection, cultured osteoblasts were washed with PBS, then serum-free DMEM containing diluted viral stock was added to wells (multiplicity of infection $=20$ ).

CSE-targeted 21-nt siRNA: forward (GGU UAU UUA UCC UGG GCU GdTdT) and reverse (CAG CCC AGG CUA AAU AAC CdTdT) RNA strands, CBS-target 21-nt siRNA: forward (UGA UGA CGA UUC CUU CGC CdTdT) and reverse (GGC GAA GGA AUC GUC AUC AdTdT), and scramble siRNA: forward (UUC UCC GAA CGU GUC ACG UdTdT) and reverse (ACG UGA CAC GUU CGG AGA AdTdT) were designed and synthesized by Sigma (St. Louis, MO). siRNA (100 pM) was transfected into osteoblasts by using siPORT lipid transfection agent. A control was scramble RNA. The CSE protein expression of all groups was confirmed by Western blot analysis.

\section{H2S generation assay}

Primary osteoblasts or knockdown CSE/CBS osteoblasts were collected, and the homogenates were prepared by potassium phosphate buffer $(50 \mathrm{mM}, \mathrm{pH} 6.8)$. Then, the homogenates $(100 \mu \mathrm{L})$ were added to cold reaction buffer (100 $\mathrm{mM}$ potassium phosphate, $\mathrm{pH} 7.4,5 \mathrm{mM}$ L-cysteine, $2 \mathrm{mM}$ pyridoxal phosphate, total volume $900 \mu \mathrm{L}$ ) and transferred into a conical flask. In the central well of the flask,
$0.5 \mathrm{~mL} 1 \%$ zinc acetate was added, and $2 \times 2 \mathrm{~cm}$ filter paper was placed in the central well to increase absorption area. N2 was filled into the flask for $20 \mathrm{~s}$ and it was quickly sealed, and then the flask was incubated at $37^{\circ} \mathrm{C}$ in a water bath for $5 \mathrm{~h}$; $20 \%$ trichloroacetic acid buffer was added into reaction buffer to stop the reaction. The zinc acetate buffer and filter paper in central well were transferred into tube and methylene blue assay was performed. For inhibitor studies, PPG $(3 \mathrm{mM})$ or AOAA (1 mM) was directly added into reaction buffer. H2S production was presented as $\mathrm{nmol} / \mathrm{min} / \mathrm{mg}$ protein.

\section{Alizarin red and ALP histochemical staining}

After 1-day adenovirus or siRNA transfection, the osteoblasts in 12-well plates were cultured in osteogenesis cocktail (DMEM with $10 \% \mathrm{FBS}, 50 \mu \mathrm{g} / \mathrm{mL}$ ascorbate, $10 \mathrm{nM}$ dexamethasone, and $2 \mathrm{mM} \beta$-glycerophosphate) for the next 12 days, then fixed with $4 \%$ formaldehyde for $10 \mathrm{~min}$, and stained with $1 \%$ Alizarin red or 5-bromo-4-chloro-3-indolyl phosphate $(165 \mu \mathrm{g} / \mathrm{mL})$ or nitrotetrazolium blue chloride $(330 \mu \mathrm{g} / \mathrm{mL})$. The number and total area of red nodules or blue colonies were measured by image analysis with ImagePro Plus 6.0.

\section{MTT proliferation assay}

After osteoblasts were cultured in osteogenesis cocktail for $0,1,2,3$, or 4 days, $10 \mu \mathrm{L}$ of $5 \mathrm{mg} / \mathrm{mL}$ MTT solution was added to each well of a 96-well plate and incubated for $4 \mathrm{~h}$, then $150 \mu \mathrm{L}$ DMSO was added and mixed thoroughly to 
dissolve the dark blue crystal, which was then read by an ultraviolet spectrophotometer at $492 \mathrm{~nm}$.

\section{Western blot analysis}

Osteoblast nuclear fractions were extracted by using the NE-PER Nuclear and Cytoplasmic Extraction Reagents Kit (Applygene, Beijing). The antibodies, anti-CSE, anti-CBS, anti-MPST, anti-BMP2, anti-OPN, anti-OPG, anti-histone 4, and anti-RUNX2, were purchased from Abcam. A standard Western blot protocol was used for measuring protein expression (25).

\section{Quantitative real-time PCR}

Total RNA extracted from osteoblast was reverse transcribed for quantitative real-time PCR (qRT-PCR) analysis with SYBR green I dye in the Mx3000 Quantitative PCR System (Stratagene). The relative expression of target genes was normalized to that of $18 \mathrm{~S}$ ribosomal RNA as an internal reference. The primers are shown in Supplementary Table S1.

\section{Electrophoretic mobility shift assay}

The double-stranded oligonucleotide probe for the $5^{\prime}$-end biotin-labeled OCN promoter osteoblast-specific cis-acting element 2 (OSE2) (5'-CTACCACCACCACAATGGACAG3', 5'-CTGTCCATTGTGGTGGTGGTAG-3') was synthesized by Thermo Fisher Scientific. Nuclear protein $(5 \mu \mathrm{g})$ extracted from osteoblast or HEK-293 cells was prepared by use of a kit (Applygene, Beijing). Anti-RUNX2 antibody was added to observe the supershift band. Electrophoretic mobility shift assay (EMSA) involved the use of the LightShift Chemiluminescent EMSA Kit (Pierce Biotechnology) (5).

\section{Chromatin immunoprecipitation}

ChIP assays involved the use of a ChIP Assay Kit (Beyotime, Beijing) with slight modifications (5). Briefly, cells were cross-linked with formaldehyde and sonicated to shear DNA. Immunoprecipitation involved $5 \mu \mathrm{g}$ anti-RUNX2 or normal mouse IgG antibody and $50 \mu \mathrm{g}$ DNA. After elution and purification, the recovered DNA samples were used as a template for real-time PCR. The primer sequences for the rat OCN promoter were forward, $5^{\prime}$-GCAGCCTCTGATTGTGTCCT$3^{\prime}$, and reverse, 5'-TGCTGCCAGGACTAATTGGG-3'.

\section{Immunoprecipitation-linked biotin-switch assay}

The protein sulfhydration assay was performed as described (27) with modifications (5). Briefly, osteoblast or HEK-293 cells treated with $\mathrm{H} 2 \mathrm{~S}$ or DTT were homogenized in RIPA lysis buffer (Sigma-Aldrich), then centrifuged at $14,000 \times g$ $\left(4^{\circ} \mathrm{C}\right)$ for $15 \mathrm{~min}$. The supernatant was collected and protein was quantified by bicinchoninic acid assay. The primary antiRUNX2 antibody $(2 \mu \mathrm{g})$ was added into the protein lysis $(1 \mathrm{mg} / \mathrm{mL})$ material containing protein A beads. After incubation overnight at $4^{\circ} \mathrm{C}$, the beads were washed and blocked with $250 \mathrm{mM}$ Hepes- $\mathrm{NaOH}$ (pH 7.7), $1 \mathrm{mM}$ EDTA, and 0.1 $\mathrm{mM}$ neocuproine (HEN) buffer (containing $2.5 \%$ sodium dodecylsulphate and $20 \mathrm{mM}$ methyl methanethiosulfonate [MMTS]) at $50^{\circ} \mathrm{C}$ for $20 \mathrm{~min}$. MMTS was then removed by precipitating proteins with acetone at $-20^{\circ} \mathrm{C}$ for $20 \mathrm{~min}$. After acetone removal, protein was resuspended in HEN buffer (containing 1\% SDS), and $4 \mathrm{mM}$ biotin-HPDP was added for incubation for $4 \mathrm{~h}$ at room temperature. Biotinylated protein was pulled down by streptavidin magnet beads and eluted by sodium dodecylsulphate-polyacrylamide gel electrophoresis loading buffer and subjected to Western blot analysis.

\section{Histological and immunohistochemical evaluation}

After being fixed and decalcified in 6\% trichloroacetic acid for 5 days, the intact or fractured femora were dehydrated with a series of ethanol rinses and a xylene rinse, then embedded in paraffin. Sections $8 \mu \mathrm{m}$ thick were cut and stained with hematoxylin and eosin (H\&E), picrosirius red, or toluidine blue. Anti-CSE antibody (1:100) was used for immunohistochemistry staining. Anti-RUX2 antibody (1:100) was used for immunofluorescence staining. Nuclei were counterstained with DAPI (Applygen, Beijing). The sections stained with H\&E were blindly scored by two authors according to the Emery scoring system (10).

\section{Statistical analysis}

Data were analyzed by analysis of variance, and significant differences were determined by the Bonferroni modification of the Student $t$-test. $p$-Value $<0.05$ was considered statistically significant. All data are presented as mean \pm standard deviation.

\section{Acknowledgments}

This work was supported by the National Basic Research Program (Grant Nos. 2014CB542302 and 2012CB517806), CAMS Innovation Fund for Medical Sciences (CIFMS, 201612M-1-006), the Natural Science Foundation of China (Grant Nos. 81470552, 81470541, 81630014 and 81670739), the Beijing Natural Science Foundation (Grant No. 7162093), Beijing Municipal Science and Technology Commission (Z151100002115050, Z151100004015176), and Beijing Municipal Commission of Education (KZ201610025028).

\section{Author Disclosure Statement}

No competing financial interests exist.

\section{References}

1. Bandyopadhyay A, Tsuji K, Cox K, Harfe BD, Rosen V, and Tabin CJ. Genetic analysis of the roles of BMP2, BMP4, and BMP7 in limb patterning and skeletogenesis. PLoS Genet 2: e216, 2006.

2. Bennett CN, Longo KA, Wright WS, Suva LJ, Lane TF, Hankenson KD, and MacDougald OA. Regulation of osteoblastogenesis and bone mass by Wnt10b. Proc Natl Acad Sci U S A 102: 3324-3329, 2005.

3. Bruderer M, Richards RG, Alini M, and Stoddart MJ. Role and regulation of RUNX2 in osteogenesis. Eur Cell Mater 28: 269-286, 2014.

4. Byon $\mathrm{CH}$ and Chen Y. Molecular mechanisms of vascular calcification in chronic kidney disease: the link between bone and the vasculature. Curr Osteoporos Rep 13: 206-215, 2015.

5. Cai J, Shi X, Wang H, Fan J, Feng Y, Lin X, Yang J, Cui Q, Tang C, Xu G, and Geng B. Cystathionine gamma lyasehydrogen sulfide increases peroxisome proliferatoractivated receptor gamma activity by sulfhydration at C139 site thereby promoting glucose uptake and lipid storage in adipocytes. Biochim Biophys Acta 1861: 419-429, 2016. 
6. Capulli M, Paone R, and Rucci N. Osteoblast and osteocyte: games without frontiers. Arch Biochem Biophys 561: 3-12, 2014.

7. Cohen-Solal KA, Boregowda RK, and Lasfar A. RUNX2 and the PI3K/AKT axis reciprocal activation as a driving force for tumor progression. Mol Cancer 14: 137, 2015.

8. Ducy $P$ and Karsenty G. Two distinct osteoblast-specific cis-acting elements control expression of a mouse osteocalcin gene. Mol Cell Biol 15: 1858-1869, 1995.

9. Ducy P, Zhang R, Geoffroy V, Ridall AL, and Karsenty G. Osf2/Cbfa1: a transcriptional activator of osteoblast differentiation. Cell 89: 747-754, 1997.

10. Emery SE, Brazinski MS, Koka A, Bensusan JS, and Stevenson $\mathrm{S}$. The biological and biomechanical effects of irradiation on anterior spinal bone grafts in a canine model. $J$ Bone Joint Surg Am 76: 540-548, 1994.

11. Gambari L, Lisignoli G, Cattini L, Manferdini C, Facchini A, and Grassi F. Sodium hydrosulfide inhibits the differentiation of osteoclast progenitor cells via NRF2-dependent mechanism. Pharmacol Res 87: 99-112, 2014.

12. Grassi F, Malik Tyagi A, Calvert JW, Gambari L, Walker LD, Yu M, Robinson J, Li JY, Lisignoli G, Vaccaro C, Adams J, and Pacifici R. Hydrogen sulfide is a novel regulator of bone formation implicated in the bone loss induced by estrogen deficiency. J Bone Miner Res 31: 949-963, 2016.

13. Huang TH, Lewis JL, Lin HS, Kuo LT, Mao SW, Tai YS, Chang MS, Ables GP, Perrone CE, and Yang RS. A methionine-restricted diet and endurance exercise decrease bone mass and extrinsic strength but increase intrinsic strength in growing male rats. J Nutr 144: 621-630, 2014.

14. Jeon EJ, Lee KY, Choi NS, Lee MH, Kim HN, Jin YH, Ryoo HM, Choi JY, Yoshida M, Nishino N, Oh BC, Lee KS, Lee $\mathrm{YH}$, and Bae SC. Bone morphogenetic protein-2 stimulates Runx2 acetylation. J Biol Chem 281: 16502-16511, 2006.

15. Jiang X, Chen Y, Lu K, Zhang H, and Fan X. GYY4137 promotes bone formation in a rabbit distraction osteogenesis model: a preliminary report. J Oral Maxillofac Surg 73: 732.e1-732.e6, 2015.

16. Kamoun P. Endogenous production of hydrogen sulfide in mammals. Amino Acids 26: 243-254, 2004

17. Kang S, Bennett CN, Gerin I, Rapp LA, Hankenson KD, and Macdougald OA. Wnt signaling stimulates osteoblastogenesis of mesenchymal precursors by suppressing CCAAT/enhancerbinding protein alpha and peroxisome proliferator-activated receptor gamma. J Biol Chem 282: 14515-14524, 2007.

18. Komori T. Regulation of bone development and maintenance by Runx2. Front Biosci 13: 898-903, 2008.

19. Komori T. Signaling networks in RUNX2-dependent bone development. J Cell Biochem 112: 750-755, 2011.

20. Komori T, Yagi H, Nomura S, Yamaguchi A, Sasaki K, Deguchi K, Shimizu Y, Bronson RT, Gao YH, Inada M, Sato M, Okamoto R, Kitamura Y, Yoshiki S, and Kishimoto T. Targeted disruption of Cbfa1 results in a complete lack of bone formation owing to maturational arrest of osteoblasts. Cell 89: 755-764, 1997.

21. Lacey DL, Timms E, Tan HL, Kelley MJ, Dunstan CR, Burgess T, Elliott R, Colombero A, Elliott G, Scully S, Hsu H, Sullivan J, Hawkins N, Davy E, Capparelli C, Eli A, Qian YX, Kaufman S, Sarosi I, Shalhoub V, Senaldi G, Guo J, Delaney J, and Boyle WJ. Osteoprotegerin ligand is a cytokine that regulates osteoclast differentiation and activation. Cell 93: 165-176, 1998.

22. Lee KS, Kim HJ, Li QL, Chi XZ, Ueta C, Komori T, Wozney JM, Kim EG, Choi JY, Ryoo HM, and Bae SC.
Runx2 is a common target of transforming growth factor beta1 and bone morphogenetic protein 2, and cooperation between Runx2 and Smad5 induces osteoblast-specific gene expression in the pluripotent mesenchymal precursor cell line C2C12. Mol Cell Biol 20: 8783-8792, 2000.

23. Lee SK, Chung JH, Choi SC, Auh QS, Lee YM, Lee SI, and Kim EC. Sodium hydrogen sulfide inhibits nicotine and lipopolysaccharide-induced osteoclastic differentiation and reversed osteoblastic differentiation in human periodontal ligament cells. J Cell Biochem 114: 1183-1193, 2013.

24. Liao $\mathrm{C}$ and Hua Y. Effect of hydrogen sulphide on the expression of osteoprotegerin and receptor activator of NFkappaB ligand in human periodontal ligament cells induced by tension-force stimulation. Arch Oral Biol 58: 1784-1790, 2013.

25. Liao F, Zheng Y, Cai J, Fan J, Wang J, Yang J, Cui Q, Xu $\mathrm{G}$, Tang $\mathrm{C}$, and Geng B. Catestatin attenuates endoplasmic reticulum induced cell apoptosis by activation type 2 muscarinic acetylcholine receptor in cardiac ischemia/reperfusion. Sci Rep 5: 16590, 2015.

26. Liu Y, Yang R, Liu X, Zhou Y, Qu C, Kikuiri T, Wang S, Zandi E, Du J, Ambudkar IS, and Shi S. Hydrogen sulfide maintains mesenchymal stem cell function and bone homeostasis via regulation of $\mathrm{Ca}(2+)$ channel sulfhydration. Cell Stem Cell 15: 66-78, 2014.

27. Mustafa AK, Gadalla MM, Sen N, Kim S, Mu W, Gazi SK, Barrow RK, Yang G, Wang R, and Snyder SH. H2S signals through protein S-sulfhydration. Sci Signal 2: ra72, 2009.

28. Orriss IR, Taylor SE, and Arnett TR. Rat osteoblast cultures. Methods Mol Biol 816: 31-41, 2012.

29. Oryan A, Monazzah S, and Bigham-Sadegh A. Bone injury and fracture healing biology. Biomed Environ Sci 28: 57-71, 2015.

30. Otto F, Thornell AP, Crompton T, Denzel A, Gilmour KC, Rosewell IR, Stamp GW, Beddington RS, Mundlos S, Olsen BR, Selby PB, and Owen MJ. Cbfa1, a candidate gene for cleidocranial dysplasia syndrome, is essential for osteoblast differentiation and bone development. Cell 89: 765-771, 1997.

31. Paul BD and Snyder SH. H2S: a novel gasotransmitter that signals by sulfhydration. Trends Biochem Sci 40: 687-700, 2015.

32. Plummer J, Park M, Perodin F, Horowitz MC, and Hens JR. Methionine-restricted diet increases miRNAs that can target RUNX2 expression and alters bone structure in young mice. J Cell Biochem 118: 31-42, 2017.

33. Titorencu I, Pruna V, Jinga VV, and Simionescu M. Osteoblast ontogeny and implications for bone pathology: an overview. Cell Tissue Res 355: 23-33, 2014.

34. Vacek TP, Qipshidze N, and Tyagi SC. Hydrogen sulfide and sodium nitroprusside compete to activate/deactivate MMPs in bone tissue homogenates. Vasc Health Risk Manag 9: 117-123, 2013.

35. van Meurs JB, Dhonukshe-Rutten RA, Pluijm SM, van der Klift M, de Jonge R, Lindemans J, de Groot LC, Hofman A, Witteman JC, van Leeuwen JP, Breteler MM, Lips P, Pols $\mathrm{HA}$, and Uitterlinden AG. Homocysteine levels and the risk of osteoporotic fracture. N Engl J Med 350: 2033-2041, 2004.

36. Vimalraj S, Arumugam B, Miranda PJ, and Selvamurugan N. Runx2: structure, function, and phosphorylation in osteoblast differentiation. Int J Biol Macromol 78: 202-208, 2015.

37. Wang R. Physiological implications of hydrogen sulfide: a whiff exploration that blossomed. Physiol Rev 92: 791-896, 2012.

38. Wu SY, Pan CS, Geng B, Zhao J, Yu F, Pang YZ, Tang CS, and Qi YF. Hydrogen sulfide ameliorates vascular calcification induced by vitamin D3 plus nicotine in rats. Acta Pharmacol Sin 27: 299-306, 2006. 
39. Xu ZS, Wang XY, Xiao DM, Hu LF, Lu M, Wu ZY, and Bian JS. Hydrogen sulfide protects MC3T3-E1 osteoblastic cells against $\mathrm{H} 2 \mathrm{O} 2$-induced oxidative damage-implications for the treatment of osteoporosis. Free Radic Biol Med 50: 1314-1323, 2011.

40. Yamaguchi A, Katagiri T, Ikeda T, Wozney JM, Rosen V, Wang EA, Kahn AJ, Suda T, and Yoshiki S. Recombinant human bone morphogenetic protein-2 stimulates osteoblastic maturation and inhibits myogenic differentiation in vitro. J Cell Biol 113: 681-687, 1991.

41. Zavaczki E, Jeney V, Agarwal A, Zarjou A, Oros M, Katko M, Varga Z, Balla G, and Balla J. Hydrogen sulfide inhibits the calcification and osteoblastic differentiation of vascular smooth muscle cells. Kidney Int 80: 731-739, 2011.

Address correspondence to: Dr. Bin Geng Hypertension Center Fuwai Hospital

Chinese Academy of Medical Sciences and Peking Union Medical College State Key Laboratory of Cardiovascular Disease National Center for Cardiovascular Diseases North Lishi Road No. 167 Xicheng District, Beijing 100037 China

E-mail: bingeng@hsc.pku.edu.cn

Prof. Jun Cai Hypertension Center Fuwai Hospital

Chinese Academy of Medical Sciences and Peking Union Medical College State Key Laboratory of Cardiovascular Disease National Center for Cardiovascular Diseases North Lishi Road No. 167

Xicheng District, Beijing 100037 China

E-mail: caijun@fuwaihospital.org
Date of first submission to ARS Central, July 13, 2016; date of final revised submission, February 2, 2017; date of acceptance, February 3, 2017.

\begin{tabular}{|c|}
\hline 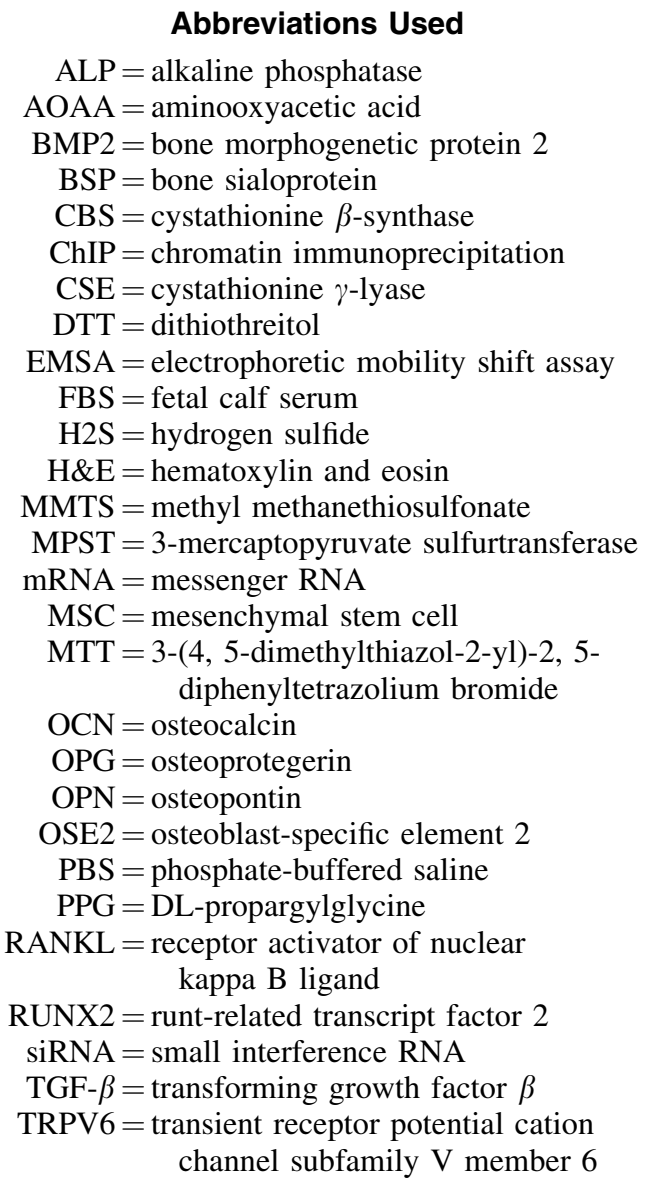 \\
\hline
\end{tabular}

